\title{
Article \\ Relationships between Copper Futures Markets from the Perspective of Jump Diffusion
}

\author{
Xue Jin ${ }^{1,2,3,4}\left(\right.$, Shiwei Zhou ${ }^{3}$, Kedong Yin ${ }^{1,2, *}$ and Mingzhen $\mathrm{Li}^{3}$ \\ 1 School of Management Science and Engineering, Shandong University of Finance and Economics, \\ Jinan 250014, China; jinxue@ouc.edu.cn \\ 2 Institute of Marine Economy and Management, Shandong University of Finance and Economics, \\ Jinan 250014, China \\ 3 School of Economics, Ocean University of China, Qingdao 266100, China; \\ zhoushiwei1213@stu.ouc.edu.cn (S.Z.); mzlosd@163.com (M.L.) \\ 4 Institute for the Oceans and Fisheries, University of British Columbia, 2202 Main Mall, \\ Vancouver, BC V6T 1Z4, Canada \\ * Correspondence: yinkedong@ouc.edu.cn
}

Citation: Jin, X.; Zhou, S.; Yin, K.; Li, M. Relationships between Copper Futures Markets from the Perspective of Jump Diffusion. Mathematics 2021, 9, 2268. https://doi.org/10.3390/ math9182268

Academic Editor: Junseok Kim

Received: 30 July 2021

Accepted: 10 September 2021

Published: 15 September 2021

Publisher's Note: MDPI stays neutral with regard to jurisdictional claims in published maps and institutional affiliations.

Copyright: (c) 2021 by the authors. Licensee MDPI, Basel, Switzerland. This article is an open access article distributed under the terms and conditions of the Creative Commons Attribution (CC BY) license (https:// creativecommons.org/licenses/by/ $4.0 /)$.

\begin{abstract}
This paper analyzes the price correlation effect between domestic and foreign copper futures contracts. The VAR-BEKK-GARCH $(1,1)$ spillover effect model and the BN-S class nonparametric model based on the jumping perspective are used. The co-integration test shows a long-term equilibrium relationship between the three copper futures markets, and the Granger causality test shows that copper futures contracts have significant two-way spillover effects between different periods in Shanghai for New York copper and unidirectional mean spillover effects for London copper. The BEKK model shows significant bidirectional fluctuation spillover effects between the futures contracts of the Shanghai, London, and New York copper markets before the stock market crash. After the crash, Shanghai and New York copper have significant one-way fluctuation spillover effects on London copper futures contracts. There are jumps within a single market, and the number of joint jumps between markets increases with the significance level.
\end{abstract}

Keywords: copper futures; jump-diffusion; spillover effect; co-movement relationship

\section{Introduction}

Owing to its outstanding ductility, thermal conductivity, and electrical conductivity, copper is widely used in various fields such as electric power, construction, home appliances, transportation, and other industries. However, there is a worldwide shortage of copper. According to the latest data from the World Bureau of Metals Statistics, the global copper market was short by 1.39 million tons in 2020. Since the beginning of 2018, the supply and demand dilemma of copper resources has been aggravated by a drop in explicit global copper inventories, difficulties in wage negotiations among copper miners, and the closure of Smelters owned by India's Vedanta. The high degree of absolute international dependence will inevitably lead to a bad situation for Chinese enterprises in the world economy and trade. As the world's largest copper consumer, China faces a shortage of mineral resources in the development process, and smelting capacity is greater than the support capability of structural problems in mines. Additionally, China's copper dispersion and resources are heavily dependent on imports; that is, the external dependency on copper of up to $80 \%$ is bound to cause adverse situations for Chinese enterprises in the global economy and trade. Copper prices have been climbing as the central environmental watchdog has carried out "look back" measures. On 15 June 2018, the U.S. announced a $25 \%$ tariff on roughly USD $\$ 50$ billion of imported goods, and China retaliated. The escalation of friction regarding trade has led to a temporary slowdown in the process of global economic growth, and risks are also increasing. 
Given the closer international metal trade relationships, metal futures, metal options, and other financial instruments are gradually being promoted, and the Shanghai futures trading market is gradually opening and has an increasingly obvious relationship with the international futures market. Copper futures are futures contracts whose subject matter is non-ferrous metal copper. Copper futures began trading on the London Metal Exchange (LME) in 1877, being the first metal futures traded on the LME. Currently, the New York Mercantile Exchange (COMEX), the LME, and the Shanghai Futures Exchange (SHFE) are the main international copper futures trading venues. Among them, The London Stock Exchange is the most well-known and the most widely referenced and researched non-ferrous metal futures circulation venue, and has become the universally recognized place for international copper prices to be set. China's copper futures trading appeared relatively late and has developed rapidly in recent years. The futures market is more and more legalized, and its international influence is constantly increasing. The price of Copper futures in Shanghai has formed a high-level linkage with other international markets, and the prices between the markets continue to spread among them. The launch of London and New York copper futures contracts will help Chinese spot traders better manage the risk of renminbi-denominated commodity contracts and establish a pricing mechanism for metals in Asia.

Therefore, from the two perspectives of diffusion and jumping, this paper precisely analyzes the price of copper futures contracts to correlation effect and compares the copper futures market strain capacity of the international market price information to promptly provide a solid operational foundation for the relevant regulatory authorities and traders and supply accurate pricing and hedging. Our data is comprised of data from 2 June 2006 to 30 June 2020 for three futures markets, including the closing prices of futures on the Shanghai Futures Exchange, The New York Futures Exchange, and the London Futures Exchange.

With the rise and development of futures markets worldwide, analysis of the price correlation effect between futures markets in various countries (or regions) has become a research focus. The theory of the linkage of commodity futures markets mainly includes the convenience theory, the inventory theory, the herd effect, and the market contagion theory. Commodity, storage loss, the opportunity cost of spot purchase, and convenience income act together in the pricing process of futures contracts. Convenience income and commodity price are positively correlated, where a higher commodity price brings higher convenience income. Spot copper, as an important industrial raw material, has a high degree of openness in the copper trade among countries, while the futures price tends to converge on the spot price, which makes the copper futures price in each market maintain its equilibrium. The study of herd behavior belongs to behavioral finance, that is, investors will adopt the same decision-making means as others when they have no way to choose their investment modes [1,2]. The International Monetary Fund believes that one of the causes of the recent financial crisis was the transmission and spread of volatility risks among countries, that is, when a country's economy fluctuates, it will trigger the rejudgment and evaluation of information by investors in other markets. This would change the prices of various financial products to a certain extent and cause the transmission of volatility between countries [3]. The forms of futures market linkages mainly include cointegration and spillover effects between market prices, and the co-integration relationship, spillover effect, and price discovery are interrelated rather than completely independent. Guangxi C. et al. proposed a correlation analysis method to measure and calculate the price relationships in different regional markets, utilizing a simple regression coefficient to calculate the correlation coefficient for measuring the degree of fusion [4]. However, the instability of the price series resulted in inaccurate model statistics, which led to significant errors. Engle R.F. and Granger C.W.J. found that the combined variance residuals of nonstationary sequences were stable and thus proposed the concept of "co-integration," which indicated a stable long-term equilibrium relationship between sequences [5]. The two-step E-G method is widely used in economics, including futures markets. The co-integration 
relationship between the grain futures market and the spot market, the grain futures markets of different countries, special dollar futures, and the United States bond futures have been verified [6-8].

On this basis, scholars began to apply combinations of various models for market linkage analysis. For example, Zhou B. and Wu C. used the VAR-DCC-MGARCH to comprehensively explore the idea that the index futures market dominates the price discovery process between the CSI 300 index futures and spot markets [9]. Chiao-Yi Chang et al. used energy futures as a research object by building the ECM-MD model, ECM-BEKK model, and six other models [10]. It was found that there is, consistently, asymmetric hedging performance between upward and downward price trends. Based on the DCC method, some researchers have developed the trend consistency of futures price fluctuations for the London and Shanghai copper markets [11,12]. Gulley and Tilton found that when the market is in a state of strong premium, investors' demand for the futures market will affect spot and futures prices, and its influence is greater than that of a weak market [13]. Yue identified that the impact of London metal pricing was more prominent based on the DCC model, while the impact of the Shanghai metal market was less prominent [14]. Mayer et al. used a bidirectional Granger causality test and EGARCH volatility analysis to find that, in the long run, trading activities have almost no impact on metal spot prices, only promoting volatility to a certain extent [15]. Song and Xing used the VECM, BEKK-GARCH, and CCC-GARCH models to find that copper futures in Shanghai, London, and New York had a co-integration correlation [16]. Moreover, the pricing mechanism of Shanghai copper is more significant, but the exchange of information between Shanghai copper futures and the outside world is insufficient. More and more researchers have built DCC-GARCH-T, VAR-DCC-GARCH, and VAR-BEKK-GARCH models to explore the relationship between the volatility spillover effect and price discovery in futures markets $[17,18]$. From a short-term perspective, price discovery shows that markets remain closely related. When one market is disturbed, price changes will spread to other markets, and different markets will show a consistent trend under this interaction. A volatility spillover is an outcome of linkage analysis, that is, market risks communicate. That is, due to the co-integration effect between different price series, various markets have volatility spillover effects, and volatility risks are transmitted between markets.

In different market environments, most investors will be affected by external factors and show irrational characteristics, thus causing the phenomenon of the market jump. Hull illustrated that the introduction of this phenomenon can improve some non-normal characteristics, that is, the form of jump diffusion perfectly describes the price changes of commodities [19]. Duffie et al. proved that affine classes in the multi-factor jump diffusion process are flexible [20]. Maosen Zhong et al. found that the Mexican futures market had a certain price discovery function, but had a negative impact on its spot market [21]. Jacod and Todorov took the conversion rate between pound sterling, mark, and U.S. dollar as the research object, and found a certain correlation between them, as well as pair jumping [22]. Gilde identified a significant correlation between the U.S. stock market and the number of joint jumps between stocks showing a relatively stable trend in the number and range of jumps [23]. Some researchers have explored the manifestation of the jump process and behavior of stock prices in various stages [24-26]. Liu and Xu compared and analyzed the detection level and efficacy of eight different jump test methods using the Monte Carlo analysis method, and found that BN-S non-parametric test methods have more advantages than the TMPV methods when there is a large fluctuation in the sample data [27]. Cao and Guernsey found that the fluctuation of crude oil and natural gas futures prices could be decomposed into an infinite active fluctuation diffusion process and a lower, but larger fluctuation process [28]. Gong et al. constructed a generalized doubleexponential distribution jump-diffusion model based on a Markov chain Monte Carlo simulation and found that it could better capture the peak and thick tail characteristics of the rate of return distribution and that the probability of the rise and fall of stock index futures returns and stock index spot returns presented asymmetry [29]. Yaoqi Guo et al. 
applied the nonlinear Granger causality and multifractal methods to test market efficiency, which found that there is a significant high-order nonlinear correlation between futures and spot markets [30]. Hui Yu et al. proposed an integrated research framework combining the grey correlation and wavelet analysis and indicated that the correlations of copper prices are dynamic and uncertain [31]. Some researchers have considered price jump behaviors such as macroscopic to microcosmic exploration and combined the introduction of the financial asset price jump component with the test of a leap in the related literature, pointing out that future jump tests should focus on high-frequency financial derivatives pricing and the trading of jumping phenomenon research to improve the jumping test's noise control [32,33].

Based on a comprehensive analysis of the literature, this study determines that domestic and foreign scholars usually study futures market correlation from three perspectives:

(1) A co-integration test and an error correction mechanism to verify the long-term and short-term equilibrium relationships between variables;

(2) The GARCH model to explore the relationship between market volatility spillover;

(3) The Granger causality test or information model to study the intensity of price discovery between markets.

However, currently, few studies combine the non-parametric test method with the futures market correlation effect analysis method from the perspectives of diffusion and jumping.

From the perspective of diffusion and jump, to clarify the reasons and paths of the interaction effect of Shanghai, New York, and London copper futures markets, and put forward feasible measures for the development of the current Chinese copper futures market, this article is organized as follows. Section 1 continues the literature review of the futures market linkage effect research. Section 2 introduces the spillover effect models from the perspectives of diffusion and jump. Section 3 presents the data and test, followed by Section 4, which shows the results of the price relationship of copper futures on three futures exchanges. Section 5 presents the most important conclusions.

The innovation of this paper includes:

(1) This paper extends other scholars' work based on the copper futures contract price before the diffusion angle of empirical research and the diffusion angle using the cointegration test, the Granger causality test, and BEKK model research, based on the future jump, from the perspective of the use of the BN-S nonparametric test method and the linkage of the copper futures price in particular market environment characteristics.

(2) This paper selects the daily closing data of copper futures from three domestic and foreign markets in the past 14 years as the research sample. The sample size is large, and the sample interval is divided into three sections from the diffusion perspective to better discuss the linkage characteristics between markets with special events as time nodes.

(3) This paper takes the interaction between the three markets as the research topic. In this paper, the Shanghai copper futures market price is taken as the benchmark, the New York copper futures price and the London copper futures price are taken as the independent variables, and empirical analysis is carried out using the ECM model and impulse response and variance decomposition, enriching the research on the linkage phenomenon between the domestic and foreign copper futures markets from the perspective of diffusion. 


\section{Setting of the Model}

\subsection{ADF Unit Root Test}

The ADF unit root test is used to judge whether the time series is stationary. In the empirical analysis, the first-order difference series of price series, $P_{t}$, is verified by linear regression, and the regression equation is shown in Equation (1):

$$
\Delta p_{t}=\alpha+\beta_{t}+\gamma p_{t-1}+\sum_{i=1}^{d} \alpha_{i} \Delta p_{t-i}+\varepsilon_{t}
$$

Among them, $d$ is the order of the difference. By testing the null hypothesis $H_{0}: \gamma=1$, if the null hypothesis is accepted, it is shown that the price series, $P_{t}$, has the unit root and is a non-stationary series; otherwise, $P_{t}$ is a stationary sequence.

\subsection{Spillover Effect Model from the Perspective of Diffusion}

2.2.1. Impulse Response and Variance Decomposition

The impulse response function and variance decomposition can be used to study the impact of the internal variables of the VAR model, caused by the disturbance of their own and external variables, to analyze the dynamic characteristics of the model.

The impulse response function is used to measure the impact of one standard deviation of the residual term of one of the variables in the VAR model on the present value and future value of all variables in the model, and this one standard deviation impact is called "impulse".

Variance decomposition is mainly the model error of any exogenous variables according to the premise that variance decomposition has a relationship with all the endogenous variable factors. In other words, it analyzes the proportion of impact force of the impulse generated by $\varepsilon_{t}$ acting on the endogenous variables and then analyzes the degree of influence of $\varepsilon_{t}$ on the endogenous variables of the model.

\subsubsection{VAR-BEKK-GARCH $(1,1)$}

In this study, the mean overflow model based on the Granger causality test and the fluctuation overflow model based on the BEKK-GARCH are constructed to measure the spillover effect from the perspective of diffusion.

The BEKK test, proposed by Engle and Kroner [34], is based on the empirical research of Baba, Engle, Kroner, and Kraft (BEKK). The advantage of the model is that there are few parameters to be estimated and the covariance matrix between the variables is assumed to be positive and definite, so it can explain the volatility spillover phenomenon among copper futures contracts in different markets [35-37]. As previously mentioned, this study constructs a ternary VAR-BEKK-GARCH $(1,1)$ model to analyze the volatility spillover effect between copper futures contracts in three markets.

The mean value equation of the BEKK model is as shown in Equation (2):

$$
\begin{gathered}
P_{\text {SHFE }, t}=\mu_{1}+\sum_{i=1}^{p} \theta_{1 i} P_{\text {SHFE }, t-i}+\sum_{i=1}^{p} \varphi_{1 i} P_{\text {COMEX }, t-i}+\sum_{i=1}^{p} \phi_{1 i} P_{L M E, t-i}+\varepsilon_{1 t} \\
P_{L M E, t}=\mu_{2}+\sum_{i=1}^{p} \theta_{2 i} P_{\text {SHFE }, t-i}+\sum_{i=1}^{p} \varphi_{2 i} P_{\text {COMEX }, t-i}+\sum_{i=1}^{p} \phi_{2 i} P_{L M E, t-i}+\varepsilon_{2 t} \\
P_{\text {COMEX }, t}=\mu_{3}+\sum_{i=1}^{p} \theta_{3 i} P_{\text {SHFE }, t-i}+\sum_{i=1}^{p} \varphi_{3 i} P_{\text {COMEX }, t-i}+\sum_{i=1}^{p} \phi_{3 i} P_{L M E, t-i}+\varepsilon_{3 t}
\end{gathered} .
$$

Among them, because VAR-BEKK-GARCH(1,1) is selected to carry out the empirical test in this paper, the value of the parameter $p$ is 1 .

Vector $P_{t}=\left(p_{S H F E, t}, p_{C O M E X, t}, p_{L M E, t}\right)^{\prime}$ represents the price of SHFE, COMEX, and LME Copper futures in phase $t$, and the disturbance term is $\varepsilon_{t}=\left(\varepsilon_{1 t}, \varepsilon_{2 t}, \varepsilon_{3 t}\right)^{\prime}$, meeting $\varepsilon_{t} \sim N\left(0, H_{t}\right)$; then, the variance equation of the BEKK model is:

$$
H_{t}=C C^{\prime}+A\left(\varepsilon_{t-1} \varepsilon_{t-1}^{\prime}\right) A^{\prime}+B H_{t-1} B^{\prime} .
$$




$$
\begin{array}{ccc}
H_{t} & =\left[\begin{array}{lll}
h_{11, t} & h_{12, t} & h_{13, t} \\
h_{21, t} & h_{22, t} & h_{23, t} \\
h_{31, t} & h_{32, t} & h_{33, t}
\end{array}\right] \quad C=\left[\begin{array}{ccc}
c_{11} & 0 & 0 \\
c_{21} & c_{22} & 0 \\
c_{31} & c_{32} & c_{33}
\end{array}\right] \\
A & =\left[\begin{array}{lll}
\alpha_{11} & \alpha_{12} & \alpha_{13} \\
\alpha_{21} & \alpha_{22} & \alpha_{23} \\
\alpha_{31} & \alpha_{32} & \alpha_{33}
\end{array}\right] & B=\left[\begin{array}{lll}
\beta_{11} & \beta_{12} & \beta_{13} \\
\beta_{21} & \beta_{22} & \beta_{23} \\
\beta_{31} & \beta_{32} & \beta_{33}
\end{array}\right] .
\end{array}
$$

Therefore, each element, $h_{i j, t}$, of matrix $H_{t}$ is the copper futures contract covariance value of markets $i$ and $j$ at time point $t$; when $i=j, h_{i i, t}$ is the variance of futures contracts at time point $\mathrm{t}$ :

$$
h_{i j, t}=\sum_{p=1}^{3} c_{i p} c_{j p}+\sum_{q=1}^{3} \sum_{p=1}^{3} \alpha_{i p} \alpha_{j q} \varepsilon_{q, t-1} \varepsilon_{p, t-1}+\sum_{q=1}^{3} \sum_{p=1}^{3} \beta_{i p} \beta_{j q} h_{p q, t-1} .
$$

The VAR-BEKK-GARCH $(1,1)$ model is estimated by the likelihood function. Assuming that the residual sequence satisfies the conditional normal distribution, the logarithmic likelihood equation is as shown in Equation (4):

$$
y(\theta)=-\frac{N M}{2} \ln (2 \pi)-\frac{1}{2} \sum_{t}^{N}\left(\ln \left|H_{t-1}\right|+\varepsilon_{t-1}^{\prime} H_{t}^{-1} \varepsilon_{t-1}\right),
$$

Among them, $M$ is the number of sequences, $N$ is the sample size, and $\theta$ is the parameter to be estimated.

This is a method to determine whether copper futures contracts in different futures markets have a volatility spillover effect. The fluctuation characteristics of copper futures contracts in a single market are derived from two parts. The first part is the residuals of copper futures contracts in this market and other markets in the past period, $\varepsilon_{i, t-1}^{2}(1 \leq i \leq 3)$, and the interaction of residuals, $\varepsilon_{i, t-1} \varepsilon_{j, t-1}$. The second part is represented by the volatility, $h_{i i, t-1}(1 \leq i \leq 3)$, and covariance, $h_{i j, t-1}(i \neq j, 1 \leq i, j \leq 3)$, of copper futures contracts in this market and other markets in the past period. The convergence characteristics of copper futures contracts are derived from the main diagonal factors, $\alpha_{i i}$, of matrix $A$ and $\beta_{i i}$ of matrix $B$, which, respectively, represent the ARCH and the GARCH effects of the price series of copper futures contracts in the market. When $\alpha_{i i}=\beta_{i i}=0$, the market copper futures contract's past variance and random disturbance term does not affect the present variance. Factors $\alpha_{i i}$ and $\beta_{i i}$ represent the spillover effect of the ARCH and GARCH types of the copper futures contract on the market. When $\alpha_{i j}=\beta_{i j}=0$, the conditional variance of market $i$ 's copper futures contract is not affected by the residual and variance of market $j$ 's copper futures contract in the past period, that is, there is no volatility spillover effect of market $j$ 's copper futures contract on market $i$ 's copper futures contract. Conversely, when $\alpha_{i j} \neq 0$ or $\beta_{i j} \neq 0$, market j's copper futures contract has a volatility spillover effect on market $i$ 's copper futures contract.

\subsection{Spillover Effect Model from Jump Perspective}

\subsubsection{BN-S Nonparametric Test}

In the empirical tests of high-frequency data for futures markets, it is generally assumed that futures price sequences conform to the process of jump diffusion. If $P_{t}$ is expressed as the logarithmic price of the copper futures contract, the jump diffusion process is shown in Equation (6):

$$
d P_{t}=\mu_{t} d t+\sigma_{t} d W_{t}+Z_{t} d N_{t}
$$

$Z_{t}$ is the jump amplitude, and there is a jump characteristic when $d N_{t}=1$.

The model assumes that if the futures price is continuous, the total variation is explained by the quadratic variation $(Q V)$. The non-jump part of the total variation is explained by the integral fluctuation (IV) and the difference between QV and IV represents the 
jump part. $\left\{p_{t, 0}, p_{t, 1}, \cdots p_{t, n}\right\}$ is the $N+1$ logarithmic price of copper futures on trading day $t$, and the return rate within each trading day is expressed as $r_{t, i}=p_{t, i}-p_{t, i-1}, i=1,2 \cdots n$; the RV of trading day $t$ is then expressed as in Equation (7):

$$
R V(t)=\sum_{i=1}^{N} r_{t, i}^{2}
$$

$R V$ is the actual volatility according to the day. If only considering the continuous part, then:

$$
\lim _{N \rightarrow \infty} R V(t)=Q V(t)=\int_{t-1}^{t} V(u) d u .
$$

If there is a jumping part, $Q V$ can be expressed as in Equation (9):

$$
Q V(t)=\int_{t-1}^{t} V(u) d u+\sum_{t-1 \leq s \leq t}\{\Delta p(s)\}^{2}
$$

Therefore, $V(u)$ and $\Delta p(s)$ represent the non-jump and jump terms of futures prices, respectively. Therefore, when the jump term exists, $R V(t)$ contains the continuous part and the jump part of trading day $t$. BPV is the consistent estimator of fluctuation under discrete conditions, namely:

$$
B P V(t)=\frac{\pi}{2}\left(\frac{N}{M-1}\right) \sum_{j=2}^{N}\left|r_{t, j}\right|\left|r_{t, j-1}\right| .
$$

If $B P V(t)>R V(t)$, then the jump term is as per Equation (10):

$$
J(t)=\max [R V(t)-B P V(t), 0] .
$$

Then, the BN-S test statistic is:

$$
z(t)=\frac{\sqrt{N}}{\sqrt{\theta \max \left(1, Q P V(t) / B P V(t)^{2}\right)}}\left(\frac{R V(t)}{B P V(t)}-1\right) \sim N(0,1) .
$$

Among them, $Q P V(t)=\left(\frac{\pi^{2}}{4}+\pi-5\right) \sum_{t-1}^{N}\left|r_{t}\right|\left|r_{t-1}\right|\left|r_{t-2}\right|\left|r_{t-3}\right|$.

The judgment criterion is that, when the value of $z(t)$ is larger than the critical value corresponding to the significance level, the futures price has a jump phenomenon on trading day $t$; conversely, there is no jumping.

\subsubsection{Correlation Analysis of Jump Spillover Intensity}

The jump spillover intensity (JSI) refers to the extent to which jumping behavior in one market affects another market in the same period. The intensity of the jump spillover between domestic and foreign copper futures markets is described according to the number of jumps produced in the three markets over a given period. The jump spillover intensity formula of the three markets is:

$$
\text { JSI }=\frac{\text { The number of jumps in three markets }}{\text { The number of overlapping observations of the three markets }} \text {. }
$$

\subsubsection{Conditional Jump Spillover Probability Analysis}

The conditional jump spillover probability (CJSP) refers to the jump behavior based on one market and whether it affects other markets on the same day. In this paper, the conditional spillover probability of the SHFE is calculated by taking COMEX and LME as the benchmark foreign markets, respectively: 
CJSP of SHFE $=\frac{\text { The number of jumps in three markets }}{\text { The number of jumps in the market COMEX or LME }}$.

\section{Data Description}

\subsection{Data Selection and Processing}

This study selects the SHFE, COMEX, and LME three-month consecutive copper futures closing prices from 2 June 2006 to 30 June 2020 as sample data. The LME and SHFE data come from the WIND database, while the COMEX data comes from Sina Finance and Economics.

This study uses the mean difference method to process the data to determine the integrity and continuity of the futures price series. It also fills the corresponding incomplete futures price data of the other two exchanges according to the trading time range of the SHFE due to the difference of futures price units in these markets (i.e., the COMEX market futures price unit is cents/lb, the LME market futures price unit is USD/ton, Shanghai copper futures price unit is yuan/ton). The monthly average exchange rate of RMB to USD is adopted. The standard of one pound equaling $1 / 2204.62$ ton is adopted to unify the copper futures price units of the three markets into USD/ton.

\subsection{Analysis of Price Jumps and Fluctuations in Copper Futures Markets}

In a study on the volatility of international copper futures prices, the peak and fat tail characteristics of the copper futures price distribution can be depicted by the GARCH model. However, with the change in pricing mechanism and the addition of more determinants, the volatility of copper futures prices continues to increase. Examining the historical course of the copper futures market, we often find that the continuous fluctuation of copper futures prices can be disrupted by some unexpected events, such as the global financial crisis of 2008, the European debt crisis of 2011, the U.S. presidential elections of 2016, the China-US trade war of 2018, and the COVID-19 epidemic in 2020.

For SHFE, COMEX, and LME, the maximum logarithmic returns are $3.42 \%, 5.06 \%$, and $4.93 \%$, respectively, while the minimum returns are $-4.01 \%,-9.11 \%$, and $-9.54 \%$, respectively. According to Figure 1, extreme events are clustered. For example, in the second half of 2008, there were obvious price fluctuations in all three markets. At the end of the financial crisis, the global economic recession had a negative impact on the trend of copper prices and also the international copper futures market. Influenced by the election of U.S. President Donald Trump in November 2016, the USD fell to a new low in that year. In December of the same year, the uncertainty of the Federal Reserve's interest rate increased and the RMB continued to depreciate, which led to a sharp surge in domestic copper prices.

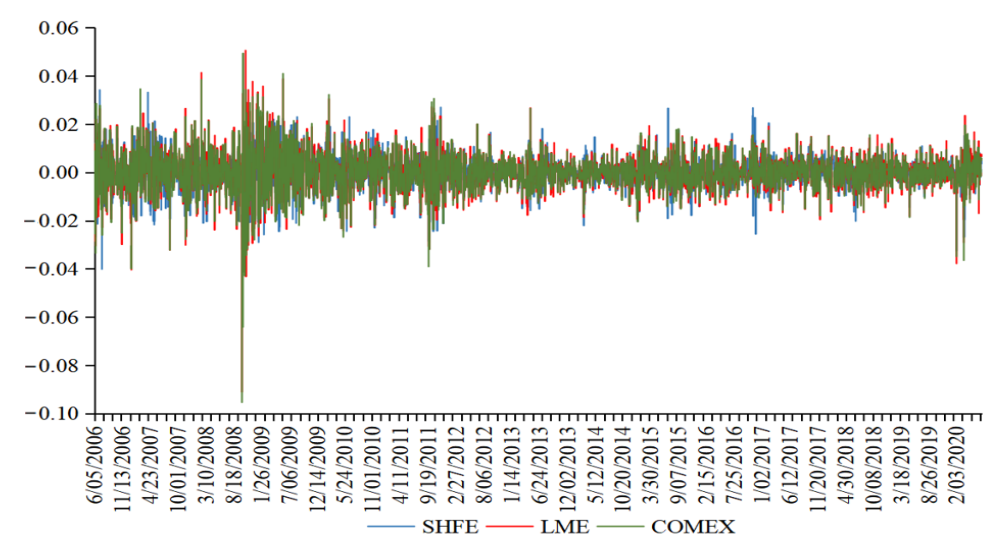

Figure 1. SHFE, COMEX, LME logarithmic return trend chart. 


\subsection{ADF Unit Root Test}

In this study, the ADF test is used to test the stationarity of the time series of different futures markets in three periods and their returns after the logarithmic first-order difference (see Tables 1-3).

Table 1. Test of unit root ADF stationarity before the 2008 financial crisis.

\begin{tabular}{ccccccc}
\hline & ADF Value & $\mathbf{1 \%}$ Level & $\mathbf{5 \%}$ Level & $\mathbf{1 0 \%}$ Level & $\boldsymbol{p}$ Value & Conclusion \\
\hline LME & -0.696462 & -3.439142 & -2.86531 & -2.568834 & 0.8454 & unstable \\
COMEX & -0.471218 & -3.439155 & -2.86532 & -2.568837 & 0.8939 & unstable \\
SHFE & -0.119847 & -3.439142 & -2.86531 & -2.568834 & 0.9453 & unstable \\
D(LME) & -28.93591 & -3.439155 & -2.86532 & -2.568837 & 0.0000 & stable \\
D(COMEX) & -30.19251 & -3.439155 & -2.86532 & -2.568837 & 0.0000 & stable \\
D(SHFE) & -16.80872 & -3.439167 & -2.86532 & -2.568837 & 0.0000 & stable \\
R LME & -28.70362 & -3.439142 & -2.86531 & -2.568834 & 0.0000 & stable \\
R COMEX & -29.94383 & -3.439155 & -2.86532 & -2.568837 & 0.0000 & stable \\
R SHFE & -16.96904 & -3.439142 & -2.86531 & -2.568834 & 0.0000 & stable \\
\hline
\end{tabular}

Note: $\mathrm{R}^{\mathrm{LME}}, \mathrm{R}^{\mathrm{COMEX}}$, and $\mathrm{R}^{\mathrm{SHFE}}$ represent the logarithmic return sequences of the copper futures market prices before the 2008 financial crisis.

Table 2. Stationarity test of unit root ADF before the end of the stock market crash after the financial crisis.

\begin{tabular}{ccccccc}
\hline & ADF Value & 1\% Level & 5\% Level & $\mathbf{1 0 \%}$ Level & $\boldsymbol{p}$ Value & Conclusion \\
\hline LME & -2.495446 & -3.433962 & -2.863022 & -2.567606 & 0.1167 & unstable \\
COMEX & -2.490141 & -3.433953 & -2.863018 & -2.567604 & 0.1180 & unstable \\
SHFE & -2.338922 & -3.433953 & -2.863018 & -2.567604 & 0.1599 & unstable \\
D(LME) & -43.47430 & -3.433969 & -2.863025 & -2.567608 & 0.0001 & stable \\
D(COMEX) & -43.35042 & -3.433955 & -2.863019 & -2.567605 & 0.0001 & stable \\
D(SHFE) & -43.09106 & -3.433955 & -2.863019 & -2.567605 & 0.0000 & stable \\
R LME & -44.47105 & -3.433962 & -2.863022 & -2.567606 & 0.0001 & stable \\
R $^{\text {COMEX }}$ & -44.06876 & -3.433953 & -2.863018 & -2.567604 & 0.0001 & stable \\
R $^{\text {SHFE }}$ & -42.20816 & -3.433953 & -2.863018 & -2.567604 & 0.0000 & stable \\
\hline
\end{tabular}

Note: $\mathrm{R}^{\mathrm{LME}}, \mathrm{R}^{\mathrm{COMEX}}$, and $\mathrm{R}^{\mathrm{SHFE}}$ represent the logarithmic return sequence of the copper futures market prices from the financial crisis in 2008 to the end of the stock market crash in 2016.

Table 3. Stationarity test of unit root ADF after the stock crash.

\begin{tabular}{ccccccc}
\hline & ADF Value & $\mathbf{1 \%}$ Level & $\mathbf{5 \%}$ Level & $\mathbf{1 0 \%}$ Level & $\boldsymbol{p}$ Value & Conclusion \\
\hline LME & -1.759239 & -3.439332 & -2.865394 & -2.568879 & 0.4009 & unstable \\
COMEX & -1.782674 & -3.439332 & -2.865394 & -2.568879 & 0.3893 & unstable \\
SHFE & -1.867387 & -3.439332 & -2.865394 & -2.568879 & 0.3479 & unstable \\
D(LME) & -27.76187 & -3.439345 & -2.865394 & -2.568882 & 0.0000 & stable \\
D(COMEX) & -26.85184 & -3.439345 & -2.865394 & -2.568882 & 0.0000 & stable \\
D(SHFE) & -27.66291 & -3.439345 & -2.865394 & -2.568882 & 0.0000 & stable \\
R $^{\text {LME }}$ & -27.67959 & -3.439345 & -2.865394 & -2.568882 & 0.0000 & stable \\
$\mathrm{R}^{\text {COMEX }}$ & -26.30751 & -3.439332 & -2.865394 & -2.568879 & 0.0000 & stable \\
$\mathrm{R}^{\text {SHFE }}$ & -27.33727 & -3.439345 & -2.865394 & -2.568882 & 0.0000 & stable \\
\hline
\end{tabular}

Note: $\mathrm{R}^{\mathrm{LME}}, \mathrm{R}^{\mathrm{COMEX}}$, and $\mathrm{R}^{\mathrm{SHFE}}$ represent the logarithmic return sequence from the stock market crash in 2016 to the copper futures market prices at the end of 2018.

In Tables 1 and 2, it is observed that the original sequences of copper futures prices in LME, COMEX, and SHFE are non-stationary at all stages. The first-order difference series is also stable, so the futures prices of LME, COMEX, and SHFE are the first-order integration, and the ADF statistic value of the first-order difference series of copper futures prices of LME and COMEX is significantly higher than that of the SHFE, indicating that the stability of domestic copper futures markets is worse than in the foreign markets. It can be seen 
from Table 3 that, at the three significance levels, each yield sequence has no unit root and is stable.

\section{Model Calibration}

4.1. Linkage Effect Analysis of Copper Futures Market from the Perspective of Diffusion 4.1.1. E-G Two-Step Co-Integration Test

Because the copper futures prices of $L M E, C O M E X$, and SHFE are all first-order, this study uses the E-G two-step method to test the long-term equilibrium relationship between $L M E, C O M E X$, and SHFE. The regression equations of co-integration are:

Phase I (from 2 June 2006 to 24 December 2008):

$$
\begin{gathered}
\text { SHFE }=1091.048+1.6782 C O M E X-0.5778 L M E+E C_{1} \\
R^{2}=0.8497 \quad F=1926.0688
\end{gathered}
$$

Phase II (from 25 December 2008 to 29 January 2016):

$$
\begin{gathered}
\text { SHFE }=376.4155-0.2620 C O M E X+1.3113 L M E+E C_{2} \\
R^{2}=0.9537 \quad F=17217.6156
\end{gathered}
$$

Phase III (from 1 February 2016 to 30 June 2020):

$$
\begin{gathered}
\text { SHFE }=312.1979+0.3639 C O M E X+0.7585 L M E+E C_{3} \\
R^{2}=0.9613 \quad F=7719.5617
\end{gathered}
$$

Unit root tests were conducted for residual sequences $E C_{1}, E C_{2}$, and $E C_{3}$ to test the existence of the co-integration relationship between the SHFE, LME, and COMEX copper futures prices. The results are shown in Table 4.

Table 4. Unit root test results of residual sequence.

\begin{tabular}{ccccccc}
\hline & ADF Value & $\mathbf{1 \%}$ Level & $\mathbf{5 \%}$ Level & $\mathbf{1 0} \%$ Level & $p$ Value & Conclusion \\
\hline $\mathrm{EC}_{1}$ & -2.6185 & -2.5682 & -1.9413 & -1.6164 & 0.0086 & stable \\
$\mathrm{EC}_{2}$ & -2.9553 & -2.5663 & -1.9410 & -1.6166 & 0.0031 & stable \\
$\mathrm{EC}_{3}$ & -6.2035 & -2.5682 & -1.9413 & -1.6164 & 0.0000 & stable \\
\hline
\end{tabular}

According to Formulas (15)-(17), the SHFE, LME, and COMEX copper futures price co-integration equation passed the significance test in all three stages. Over time, the constant terms decrease even more.

According to Table 4, the unit root test values of the EC sequences in the three stages are all lower than the critical values at various significance levels; that is, EC sequences are stationary. Therefore, at a certain significance level, SHFE, LME, and COMEX copper futures prices show long-term co-integration; that is, there is no arbitrage equilibrium relationship between the three markets.

\subsubsection{Error Correction Model}

To improve the model accuracy, residual series $\mathrm{EC}_{1}, \mathrm{EC}_{2}$, and $\mathrm{EC}_{3}$ are regarded as equilibrium errors to construct the ECM model, which comprehensively reflects the instantaneous change and long-term development of copper futures prices in the three markets over the three stages.

Phase I (from 2 June 2006 to 24 December 2008):

$$
\begin{gathered}
\Delta S H F E_{t}=-2.5418+0.4010 \Delta C O M E X_{t}+0.1816 \Delta L M E_{t}-0.0201 E C_{1, t-1} \\
R^{2}=0.3091 \quad F=103.4706
\end{gathered}
$$


Phase II (from 25 December 2008 to 29 January 2016):

$$
\begin{gathered}
\Delta S H F E_{t}=0.7004+0.4668 \Delta C O M E X_{t}+0.0077 \Delta L M E_{t}-0.0223 E C_{2, t-1} \\
R^{2}=0.2489 \quad F=179.9349
\end{gathered}
$$

Phase III (from 1 February 2016 to 30 June 2020):

$$
\begin{gathered}
\Delta S H F E_{t}=1.6195+0.4586 \Delta C O M E X_{t}+0.0976 \Delta L M E_{t}-0.0513 E C_{3, t-1} \\
R^{2}=0.2971 \quad F=94.5127
\end{gathered}
$$

The error series coefficients of Shanghai copper futures prices in the three stages are all below zero, indicating there is an automatic adjustment mechanism for the price of Shanghai copper futures to improve the short-term fluctuation in the long-term equilibrium. Additionally, the absolute value of the error correction coefficient increases from 0.0201 to 0.0223 and 0.0513 , indicating that the rate of long-term equilibrium adjustment in the copper futures market is accelerating.

\subsubsection{Impulse Response and Variance Decomposition}

Eviews software was used to determine the optimal lag order by the AIC and SC criteria, and the VAR model of the three-stage copper futures price logarithmic return rate was constructed. Impulse response and variance decomposition analyses were performed based on the unit circle test.

Phase I (from 2 June 2006 to 24 December 2008):

$$
R_{t}=\left[\begin{array}{ccc}
-0.2530 & 0.2724 & 0.2187 \\
0.1512 & -0.3138 & 0.1965 \\
0.1001 & 0.3011 & -0.3875
\end{array}\right] R_{t-1}+\left[\begin{array}{ccc}
0.0251 & 0.0067 & 0.1968 \\
0.0506 & -0.1212 & 0.0455 \\
0.0488 & 0.1471 & -0.1787
\end{array}\right] R_{t-2}+\varepsilon_{1 t},
$$

Phase II (from 25 December 2008 to 29 January 2016):

$$
\begin{aligned}
& R_{t}=\left[\begin{array}{ccc}
-0.4285 & 0.4462 & 0.1446 \\
0.1058 & -0.0571 & -0.0545 \\
0.0798 & 0.5503 & -0.6303
\end{array}\right] R_{t-1}+\left[\begin{array}{ccc}
-0.1580 & 0.2127 & 0.0861 \\
0.0597 & -0.0397 & -0.0352 \\
0.0455 & 0.3609 & -0.4044
\end{array}\right] R_{t-2} \\
& +\left[\begin{array}{ccc}
-0.0348 & 0.0707 & 0.0502 \\
0.0037 & -0.0412 & -0.0735 \\
0.0271 & 0.2611 & -0.2838
\end{array}\right] R_{t-3}+\varepsilon_{2 t}
\end{aligned}
$$

Phase III (from 1 February 2016 to 30 June 2020):

$$
R_{t}=\left[\begin{array}{ccc}
-0.4579 & 0.3981 & 0.2685 \\
0.0071 & 0.0290 & -0.0263 \\
0.0278 & 0.4332 & -0.4400
\end{array}\right] R_{t-1}+\left[\begin{array}{ccc}
-0.1687 & 0.1779 & 0.1980 \\
0.0249 & -0.0249 & 0.0331 \\
0.0542 & 0.2298 & -0.1849
\end{array}\right] R_{t-2}+\varepsilon_{3 t}
$$

The results of the stability test of the three-stage VAR model are shown in Figure 2.
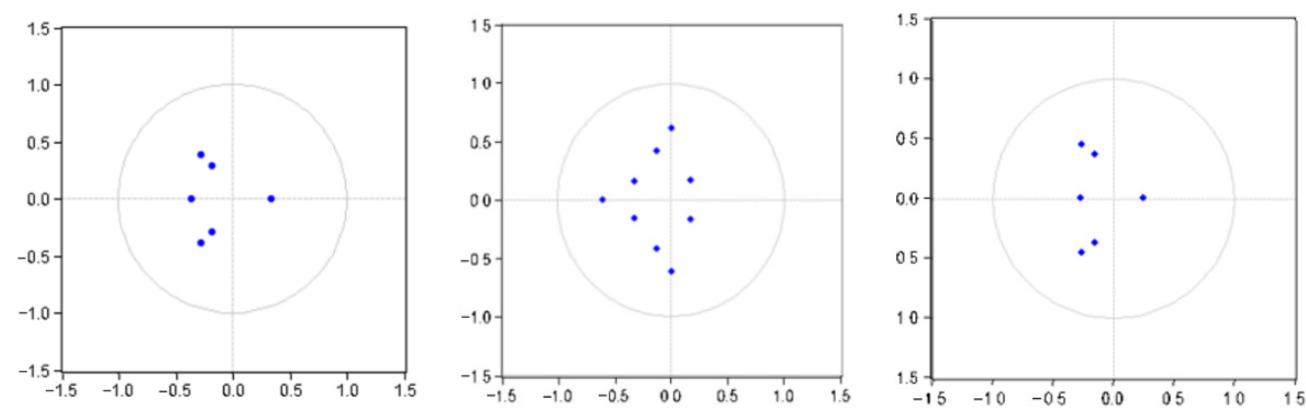

Figure 2. Unit circle of the VAR model in three stages. 
In Figure 2, it is observed that all points are concentrated in the interior of the unit circle, indicating that the VAR model is stable in the three stages and can be used for impulse response and variance decomposition analysis.

For Phase I (from 2 June 2006 to 24 December 2008), the results of the impulse response and variance decomposition are shown in Figures 3 and 4.

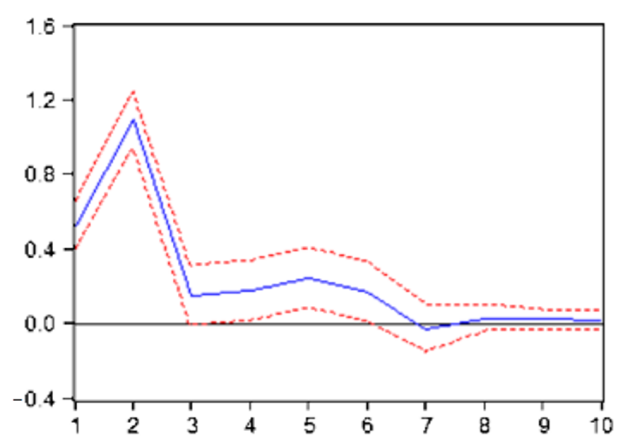

Figure 3. Impulse response of Shanghai copper to New York copper yield.

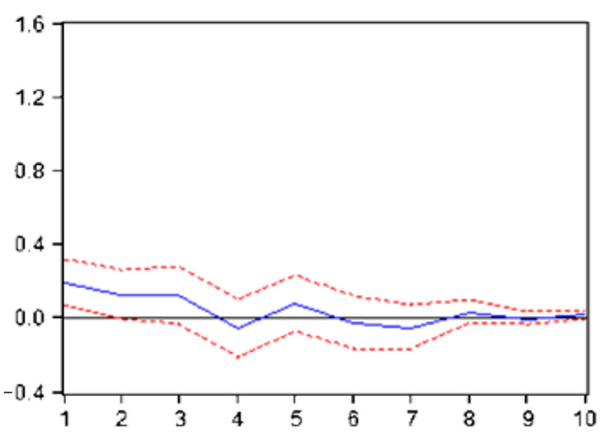

Figure 4. Impulse response of Shanghai copper to London copper yield.

Figure 3 shows that the initial impact of New York copper on the futures price of Shanghai copper is 0.53 . The impact rapidly rises to the peak in the second period and then decreases rapidly. Subsequently, it remains horizontal from the third to the seventh period, and then decreases slowly until it reaches 0 .

Figure 4 indicates that the initial impact of London copper on the futures price of Shanghai copper is 0.19 , and the effect decreases slowly and continuously. From the fourth period onward, the impact effect is not significant, gradually converging to 0 .

Table 5 indicates that the variance of the sequence of Shanghai copper return rate in the first period is entirely caused by its disturbance, while $65-67 \%$ in the second to tenth periods are caused by its disturbance, which still plays a major role until the tenth period. The variance of the New York copper yield sequence in periods 1-10 is caused by its disturbance, and the contribution rate of Shanghai copper to the New York copper yield sequence is around $9 \%$, which is much higher than that of the London copper yield sequence. Around $78 \%$ of the variance of the London copper return sequence in the first to tenth periods is caused by the disturbance of the Shanghai copper return sequence, $10 \%$ of the disturbance is caused by the New York copper return sequence, and only $12 \%$ is caused by its disturbance. 
Table 5. Variance decomposition of logarithmic return rate of copper futures in three markets in the first stage.

\begin{tabular}{|c|c|c|c|c|}
\hline \multicolumn{5}{|c|}{$R_{t}^{S H F E}$ Variance Decomposition } \\
\hline Period & S.E. & $R_{t}^{S H F E}$ & $R_{t}^{C O M E X}$ & $R_{t}^{L M E}$ \\
\hline 1 & 1.7332 & 100.0000 & 0.0000 & 0.0000 \\
\hline 2 & 2.1236 & 67.1676 & 32.0504 & 0.7821 \\
\hline 3 & 2.1350 & 67.0126 & 31.9555 & 1.0319 \\
\hline 4 & 2.1443 & 66.4384 & 32.4861 & 1.0755 \\
\hline 5 & 2.1607 & 65.4471 & 33.3414 & 1.2114 \\
\hline 6 & 2.1715 & 65.4332 & 33.3310 & 1.2358 \\
\hline 7 & 2.1722 & 65.3904 & 33.3205 & 1.2892 \\
\hline 8 & 2.1727 & 65.3618 & 33.3231 & 1.3151 \\
\hline 9 & 2.1729 & 65.3504 & 33.3345 & 1.3151 \\
\hline 10 & 2.1731 & 65.3446 & 33.3349 & 1.3205 \\
\hline \multicolumn{5}{|c|}{$R_{t}^{C O M E X}$ variance decomposition } \\
\hline Period & S.E. & $R_{t}^{S H F E}$ & $R_{t}^{C O M E X}$ & $R_{t}^{L M E}$ \\
\hline 1 & 2.6105 & 9.4667 & 90.5333 & 0.0000 \\
\hline 2 & 2.6433 & 9.7289 & 89.8387 & 0.4324 \\
\hline 3 & 2.6452 & 9.7251 & 89.7607 & 0.5142 \\
\hline 4 & 2.6470 & 9.7565 & 89.7249 & 0.5186 \\
\hline 5 & 2.6635 & 9.6478 & 89.8191 & 0.5331 \\
\hline 6 & 2.6749 & 9.7197 & 89.7452 & 0.5351 \\
\hline 7 & 2.6780 & 9.6986 & 89.7658 & 0.5356 \\
\hline 8 & 2.6780 & 9.6986 & 89.7654 & 0.5360 \\
\hline 9 & 2.6782 & 9.6975 & 89.7659 & 0.5366 \\
\hline 10 & 2.6784 & 9.6964 & 89.7664 & 0.5372 \\
\hline \multicolumn{5}{|c|}{$R_{t}^{L M E}$ variance decomposition } \\
\hline Period & S.E. & $R_{t}^{S H F E}$ & $R_{t}^{C O M E X}$ & $R_{t}^{L M E}$ \\
\hline 1 & 2.4731 & 10.7091 & 78.3238 & 10.9672 \\
\hline 2 & 2.5048 & 10.6409 & 76.4466 & 12.9125 \\
\hline 3 & 2.5059 & 10.6604 & 76.4083 & 12.9313 \\
\hline 4 & 2.5092 & 10.8034 & 76.2449 & 12.9518 \\
\hline 5 & 2.5302 & 10.7549 & 76.5025 & 12.7427 \\
\hline 6 & 2.5400 & 10.8298 & 76.4914 & 12.6788 \\
\hline 7 & 2.5419 & 10.8253 & 76.4927 & 12.6821 \\
\hline 8 & 2.5421 & 10.8239 & 76.4830 & 12.6931 \\
\hline 9 & 2.5423 & 10.8219 & 76.4874 & 12.6907 \\
\hline 10 & 2.5426 & 10.8224 & 76.4891 & 12.6885 \\
\hline
\end{tabular}

For Phase II (from 25 December 2008 to 29 January 2016), the results of the impulse response and variance decomposition are shown in Figures 5 and 6.

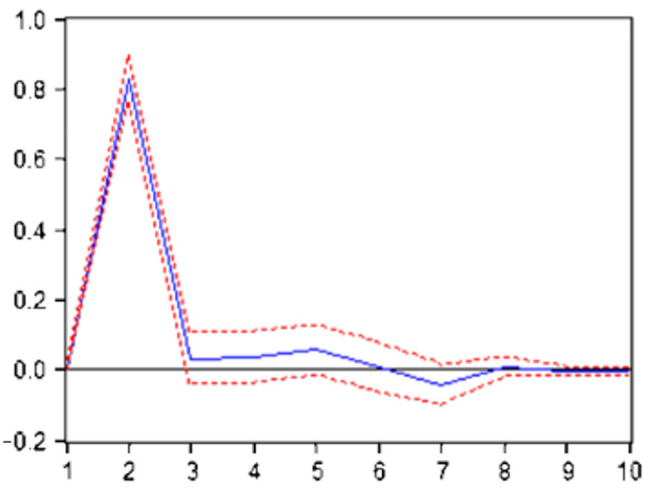

Figure 5. The impulse response of SHFE to COMEX copper yield. 


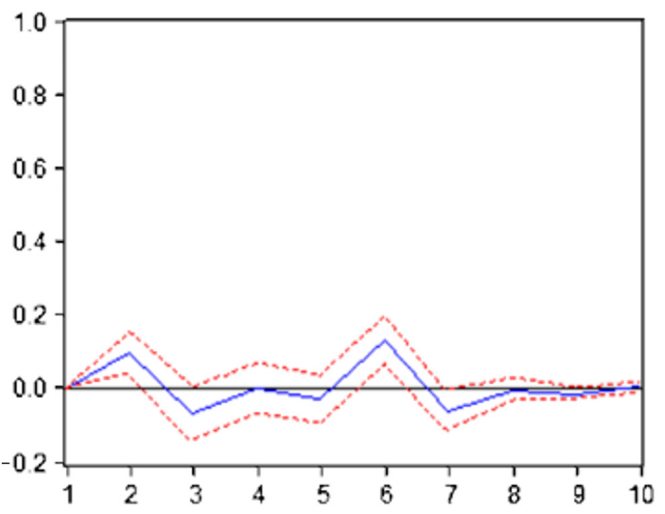

Figure 6. Impulse response of SHFE to LME copper yield.

Figure 5 shows that the initial impact of New York copper on the yield of Shanghai copper is zero, then increasing to a peak of 0.83 in the second period. The impact of the third period is already weaker, and that of the sixth period is not significant. Figure 6 indicates that the impact of London copper on the return rate of Shanghai copper is zero at the beginning, the impacts from the first to the eighth periods are alternately positive and negative, and the impact from the eighth period is not significant.

In Table 6, it is observed that the variance of the sequence of Shanghai copper return rate in the first period is caused by its disturbance. In the second and tenth periods, $67 \%$ to $68 \%$ of the disturbances are caused by itself, and around $31 \%$ of the disturbance is caused by New York copper, which is significantly greater than the effect of the London copper return rate. The variance of the New York copper yield sequence in periods 1-10 is caused by a disturbance of $76 \%$, while the Shanghai copper yield sequence contributes by around $23 \%$. Only a quarter of the variation in the copper yield sequence in London is caused by itself; around $46 \%$ of the disturbance is caused by the New York copper yield, and 25\% of the disturbance is from the Shanghai copper yield sequence.

Table 6. Variance decomposition of copper returns in three markets in the second stage.

\begin{tabular}{ccccc}
\hline \multicolumn{5}{c}{$R_{t}^{\text {SHFE }}$ Variance Decomposition } \\
\hline Period & S.E. & $R_{t}^{S H F E}$ & $R_{t}^{C O M E X}$ & $R_{t}^{L M E}$ \\
\hline 1 & 1.2211 & 100.0000 & 0.0000 & 0.0000 \\
2 & 1.4796 & 68.2009 & 31.3565 & 0.4426 \\
3 & 1.4828 & 68.0904 & 31.2560 & 0.6536 \\
4 & 1.4833 & 68.0547 & 31.2916 & 0.6537 \\
5 & 1.4848 & 67.9464 & 31.3636 & 0.6900 \\
6 & 1.4915 & 67.4100 & 31.0818 & 1.5083 \\
7 & 1.4939 & 67.2694 & 31.0760 & 1.6546 \\
8 & 1.4939 & 67.2684 & 31.0770 & 1.6546 \\
9 & 1.4940 & 67.2612 & 31.0750 & 1.6639 \\
10 & 1.4940 & 67.2599 & 31.0746 & 1.6655 \\
\hline
\end{tabular}


Table 6. Cont.

\begin{tabular}{ccccc}
\hline \multicolumn{5}{c}{$R_{t}^{C O M E X}$ variance decomposition } \\
\hline Period & S.E. & $R_{t}^{S H F E}$ & $R_{t}^{C O M E X}$ & $R_{t}^{L M E}$ \\
\hline 1 & 1.7081 & 23.4544 & 76.5457 & 0.0000 \\
2 & 1.7153 & 23.3049 & 76.6654 & 0.0297 \\
3 & 1.7156 & 23.2984 & 76.6381 & 0.0636 \\
4 & 1.7167 & 23.3231 & 76.6041 & 0.0728 \\
5 & 1.7184 & 23.2993 & 76.4704 & 0.2302 \\
6 & 1.7202 & 23.3533 & 76.3567 & 0.2900 \\
7 & 1.7213 & 23.3225 & 76.2541 & 0.4235 \\
8 & 1.7214 & 23.3222 & 76.2532 & 0.4246 \\
9 & 1.7214 & 23.3218 & 76.2527 & 0.4255 \\
10 & 1.7214 & 23.3215 & 76.2521 & 0.4264 \\
\hline & & $R_{t}^{L M E}$ variance decomposition & \\
\hline Period & S.E. & $R_{t}^{S H F E}$ & $R_{t}^{C O M E X}$ & $R_{t}^{L M E}$ \\
\hline 1 & 1.5957 & 28.3818 & 50.4062 & 21.2120 \\
2 & 1.6739 & 25.7980 & 46.1843 & 28.0178 \\
3 & 1.6744 & 25.7912 & 46.1708 & 28.0380 \\
4 & 1.6748 & 25.7925 & 46.1567 & 28.0508 \\
5 & 1.6779 & 25.6980 & 45.9946 & 28.3073 \\
6 & 1.6789 & 25.6682 & 45.9690 & 28.3628 \\
7 & 1.6791 & 25.6817 & 45.9563 & 28.3621 \\
8 & 1.6803 & 25.6468 & 45.8938 & 28.4595 \\
9 & 1.6803 & 25.6463 & 45.8938 & 28.4599 \\
10 & 1.6803 & 25.6461 & 45.8944 & 28.4595 \\
\hline
\end{tabular}

For Phase III (from 1 February 2016 to 30 June 2020), the results of the impulse response and variance decomposition are shown in Figures 7 and 8 .

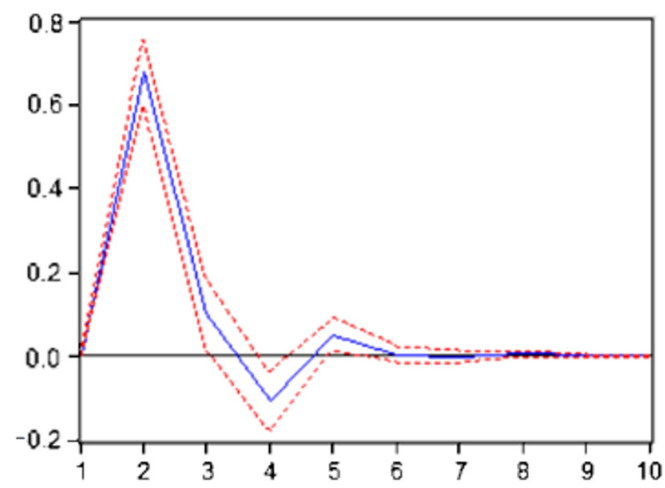

Figure 7. Impulse response of Shanghai copper to New York copper return rate.

In Figure 7, it is observed that the initial impact of new copper on the yield of Shanghai copper is zero; it then rises to a peak value of 0.67 in the second period. The impact from the third to the sixth periods presents positive and negative values, while the impact from the sixth period onward is no longer significant.

Figure 8 indicates that the impact of London copper on the yield of Shanghai copper is zero at the beginning, and then there are alternating positive and negative impacts in periods $2-6$, with an insignificant impact from period 6 onwards. 


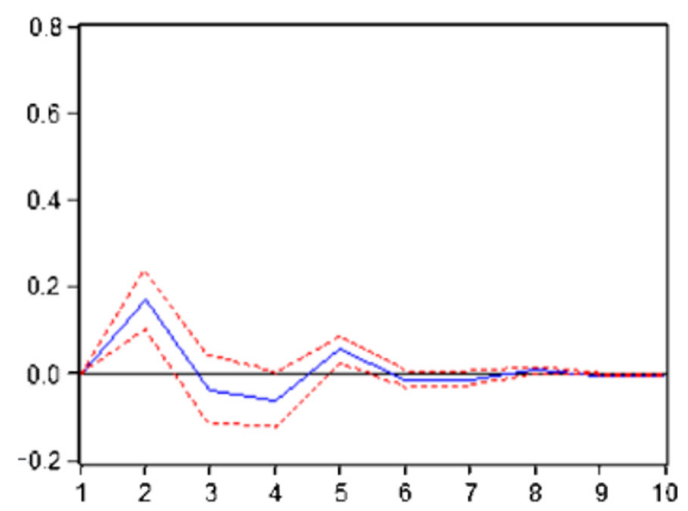

Figure 8. Impulse response of Shanghai copper to London copper return rate.

From Table 7, the variance of the sequence of the Shanghai copper return rate in the first period is caused by its disturbance. In the second to tenth periods, $61-62 \%$ of the disturbances are caused by themselves, while around $36 \%$ of the disturbance contributions are from the sequence of New York copper return rates. The variance of the New York copper yield sequence in periods $1-10$ is caused $85 \%$ by its disturbance, while the contribution rate of the Shanghai copper yield sequence is only $14 \%$. The variance of the run-copper yield sequence is approximately $35 \%$, while the disturbance contribution rates of the New York and Shanghai copper yields are $46 \%$ and $19 \%$, respectively.

Table 7. Variance decomposition of copper returns in three markets in the second stage.

\begin{tabular}{ccccc}
\hline \multicolumn{5}{c}{$R_{t}^{S H F E}$ Variance Decomposition } \\
\hline Period & S.E. & $R_{t}^{S H F E}$ & $R_{t}^{C O M E X}$ & $R_{t}^{L M E}$ \\
\hline 1 & 0.8927 & 100.0000 & 0.0000 & 0.0000 \\
2 & 1.1346 & 62.4519 & 35.2077 & 2.3404 \\
3 & 1.1421 & 62.0782 & 35.5199 & 2.4020 \\
4 & 1.1487 & 61.3677 & 35.9836 & 2.6487 \\
5 & 1.1512 & 61.1083 & 36.0172 & 2.8745 \\
6 & 1.1512 & 61.1015 & 36.0133 & 2.8851 \\
7 & 1.1513 & 61.0947 & 36.0118 & 2.8935 \\
8 & 1.1513 & 61.0902 & 36.0099 & 2.8999 \\
9 & 1.1513 & 61.0900 & 36.0098 & 2.9001 \\
10 & 1.1514 & 61.0899 & 36.0098 & 2.9004 \\
\hline Period & \multicolumn{2}{c}{$R_{t}^{C O M E X}$} & variance decomposition & \\
\hline 1 & S.E. & $R_{t}^{S H F E}$ & $R_{t}^{C O M E X}$ & $R_{t}^{L M E}$ \\
\hline 2 & 1.2466 & 14.0509 & 85.9491 & 0.0000 \\
3 & 1.2468 & 14.0490 & 85.9323 & 0.0187 \\
4 & 1.2475 & 14.0823 & 85.8428 & 0.0749 \\
5 & 1.2477 & 14.0788 & 85.8452 & 0.0760 \\
6 & 1.2477 & 14.0792 & 85.8439 & 0.0769 \\
7 & 1.2477 & 14.0790 & 85.8438 & 0.0772 \\
8 & 1.2477 & 14.0790 & 85.8438 & 0.0772 \\
9 & 1.2477 & 14.0790 & 85.8438 & 0.0772 \\
10 & 1.2477 & 14.0790 & 85.8438 & 0.0772 \\
\hline & 1.2477 & 14.0790 & 85.8438 & 0.0772 \\
\hline
\end{tabular}


Table 7. Cont.

\begin{tabular}{ccccc}
\hline \multicolumn{5}{c}{$R_{t}^{L M E}$ variance decomposition } \\
\hline Period & S.E. & $R_{t}^{S H F E}$ & $R_{t}^{C O M E X}$ & $R_{t}^{L M E}$ \\
\hline 1 & 1.1472 & 20.3571 & 47.8926 & 31.7504 \\
2 & 1.1916 & 18.8687 & 46.0038 & 35.1275 \\
3 & 1.1955 & 19.0003 & 46.1055 & 34.8942 \\
4 & 1.1978 & 18.9467 & 45.9614 & 35.0919 \\
5 & 1.1982 & 18.9365 & 45.9342 & 35.1293 \\
6 & 1.1982 & 18.9363 & 45.9341 & 35.1296 \\
7 & 1.1982 & 18.9351 & 45.9309 & 35.1340 \\
8 & 1.1982 & 18.9349 & 45.9305 & 35.1346 \\
9 & 1.1982 & 18.9349 & 45.9305 & 35.1346 \\
10 & 1.1982 & 18.9349 & 45.9304 & 35.1347 \\
\hline
\end{tabular}

In summary, in the early stages of each period, the impact of copper on Shanghai copper increased rapidly and reached its peak impact in the second period, then the impact decreased rapidly and started to be insignificant around the sixth period. However, the impact of London copper on Shanghai copper was small, alternating positive and negative impacts, and began to be insignificant around the eighth period. Therefore, the impulse response of Shanghai copper to New York copper is greater than that of London copper, and the effect of Shanghai copper on New York copper is more significant.

\subsubsection{Mean Spillover Model}

This study uses the Granger causality test to investigate the mean spillover effect of copper futures yields between the three markets. The test results are shown in Table 8 .

Table 8. Granger causality tests of three markets at different stages.

\begin{tabular}{|c|c|c|c|c|c|c|c|}
\hline \multirow[b]{2}{*}{ Relationships } & \multirow[t]{2}{*}{ Lags } & \multicolumn{2}{|c|}{$\begin{array}{c}\text { From } 2 \text { June } 2006 \text { to } 24 \\
\text { December } 2008\end{array}$} & \multicolumn{2}{|c|}{$\begin{array}{l}\text { From } 25 \text { December } 2008 \\
\text { to } 29 \text { January } 2016\end{array}$} & \multicolumn{2}{|c|}{$\begin{array}{c}\text { From } 1 \text { February } 2016 \text { to } \\
30 \text { June } 2020\end{array}$} \\
\hline & & F Value & $p$ Value & F Value & $p$ Value & F Value & $p$ Value \\
\hline \multirow{5}{*}{$\begin{array}{c}R_{t}^{L M E} \text { has no mean spillover } \\
\text { effect on } R_{t}^{C O M E X}\end{array}$} & 1 & 3.6938 & 0.0550 & 0.2000 & 0.6549 & 0.2731 & 0.6014 \\
\hline & 2 & 2.1750 & 0.1144 & 0.4184 & 0.6582 & 0.3882 & 0.6784 \\
\hline & 3 & 1.5832 & 0.1921 & 0.6370 & 0.5912 & 0.5181 & 0.6700 \\
\hline & 4 & 1.2037 & 0.3079 & 0.6258 & 0.6441 & 0.5283 & 0.7150 \\
\hline & 5 & 1.0616 & 0.3805 & 1.1355 & 0.3393 & 0.4925 & 0.7820 \\
\hline \multirow{5}{*}{$\begin{array}{l}R_{t}^{C O M E X} \text { has no mean } \\
\text { spillover effect on } R_{t}^{L M E}\end{array}$} & 1 & 6.3867 & 0.0017 & 89.8924 & 0.0000 & 43.5400 & 0.0000 \\
\hline & 2 & 4.5593 & 0.0098 & 60.9851 & 0.0000 & 29.6510 & 0.0000 \\
\hline & 3 & 3.1758 & 0.0100 & 51.8876 & 0.0000 & 22.1404 & 0.0000 \\
\hline & 4 & 4.1454 & 0.0025 & 41.2076 & 0.0000 & 17.9029 & 0.0000 \\
\hline & 5 & 3.3346 & 0.0055 & 33.0448 & 0.0000 & 14.8851 & 0.0000 \\
\hline \multirow{5}{*}{$\begin{array}{c}R_{t}^{L M E} \text { has no mean spillover } \\
\text { effect on } R_{t}^{S H F E}\end{array}$} & 1 & 248.343 & 0.0000 & 476.114 & 0.0000 & 236.429 & 0.0000 \\
\hline & 2 & 148.872 & 0.0000 & 285.952 & 0.0000 & 173.678 & 0.0000 \\
\hline & 3 & 102.099 & 0.0000 & 197.327 & 0.0000 & 122.374 & 0.0000 \\
\hline & 4 & 84.5006 & 0.0000 & 146.972 & 0.0000 & 91.3756 & 0.0000 \\
\hline & 5 & 70.0111 & 0.0000 & 122.049 & 0.0000 & 72.6690 & 0.0000 \\
\hline \multirow{5}{*}{$\begin{array}{c}R_{t}^{S H F E} \text { has no mean } \\
\text { spillover effect on } R_{t}^{L M E}\end{array}$} & 1 & 2.6667 & 0.1029 & 4.2033 & 0.0405 & 1.7309 & 0.1887 \\
\hline & 2 & 2.1102 & 0.1220 & 2.9474 & 0.0500 & 0.7546 & 0.4706 \\
\hline & 3 & 2.4384 & 0.0634 & 3.5087 & 0.0148 & 0.6897 & 0.5585 \\
\hline & 4 & 1.3954 & 0.2339 & 2.7600 & 0.0264 & 0.8669 & 0.4834 \\
\hline & 5 & 1.4162 & 0.2162 & 2.2517 & 0.0470 & 0.6420 & 0.6677 \\
\hline \multirow{5}{*}{$\begin{array}{c}R_{t}^{C O M E X} \text { has no mean } \\
\text { spillover effect on } R_{t}^{S H F E}\end{array}$} & 1 & 265.362 & 0.0000 & 620.903 & 0.0000 & 304.017 & 0.0000 \\
\hline & 2 & 154.383 & 0.0000 & 379.835 & 0.0000 & 207.572 & 0.0000 \\
\hline & 3 & 107.049 & 0.0000 & 264.713 & 0.0000 & 141.880 & 0.0000 \\
\hline & 4 & 86.6900 & 0.0000 & 202.704 & 0.0000 & 107.735 & 0.0000 \\
\hline & 5 & 72.0386 & 0.0000 & 163.908 & 0.0000 & 86.5890 & 0.0000 \\
\hline
\end{tabular}


Table 8. Cont.

\begin{tabular}{|c|c|c|c|c|c|c|c|}
\hline \multirow[b]{2}{*}{ Relationships } & \multirow{2}{*}{ Lags } & \multicolumn{2}{|c|}{$\begin{array}{c}\text { From } 2 \text { June } 2006 \text { to } 24 \\
\text { December } 2008\end{array}$} & \multicolumn{2}{|c|}{$\begin{array}{c}\text { From } 25 \text { December } 2008 \\
\text { to } 29 \text { January } 2016\end{array}$} & \multicolumn{2}{|c|}{$\begin{array}{c}\text { From } 1 \text { February } 2016 \text { to } \\
30 \text { June } 2020\end{array}$} \\
\hline & & F Value & $p$ Value & F Value & $p$ Value & F Value & $p$ Value \\
\hline \multirow{5}{*}{$\begin{array}{l}R_{t}^{S H F E} \text { has no mean } \\
\text { spillover effect on } R_{t}^{C O M E X}\end{array}$} & 1 & 5.9087 & 0.0153 & 2.8430 & 0.0920 & 0.0076 & 0.9307 \\
\hline & 2 & 4.3469 & 0.0133 & 3.1819 & 0.0418 & 0.2478 & 0.7806 \\
\hline & 3 & 3.6727 & 0.0120 & 2.2085 & 0.0853 & 0.7365 & 0.5305 \\
\hline & 4 & 2.6607 & 0.0317 & 1.7461 & 0.1372 & 0.9615 & 0.4280 \\
\hline & 5 & 2.2571 & 0.0472 & 1.5151 & 0.1819 & 0.8334 & 0.5261 \\
\hline
\end{tabular}

Table 8 shows that, at the $1 \%$ significance level, there is a significant bidirectional mean spillover effect between LME copper and COMEX copper during the entire sample period (from 2 June 2006 to 30 June 2020) and a unidirectional mean spillover effect between COMEX copper and SHFE copper. At the 5\% significance level, before the end of the financial crisis (from 2 June 2006 to 24 December 2008), there was a one-way mean spillover effect between Shanghai copper and New York copper. Before the stock market crash after the financial crisis (from 25 December 2008 to 29 January 2016), there was a one-way mean spillover effect between Shanghai copper and London copper. At the $10 \%$ significance level, before the end of the financial crisis (from 2 June 2006 to 24 December 2008), there was a one-way mean spillover effect from Shanghai copper to New York copper in the first lag period and from Shanghai copper to New York copper in the third lag period. Before the stock market crash after the financial crisis (from 25 December 2008 to 29 January 2016), there was a one-way mean spillover effect from Shanghai copper to New York copper in the first and third lag periods.

\subsubsection{Wave Spillover Model}

This study uses WinRats software to analyze the fluctuation spillover effect in three stages for the three markets. Phase I (from 2 June 2006 to 24 December 2008) is shown in Table 9.

Table 9. BEKK variance equation estimation results in the first stage.

\begin{tabular}{cccccccccc}
\hline Factor & E-Value & S.E. & T Statistic & $p$ Value & Factor & E-Value & S.E. & T Statistic & $p$ Value \\
\hline$c_{11}$ & 0.3381 & 0.0683 & 4.9528 & 0.0000 & $\alpha_{31}$ & -0.3407 & 0.0836 & -4.0766 & 0.0000 \\
$c_{21}$ & 0.2003 & 0.1712 & 1.1703 & 0.2419 & $\alpha_{32}$ & 0.2677 & 0.1456 & 1.8379 & 0.0661 \\
$c_{22}$ & 0.4572 & 0.1479 & 3.0925 & 0.0020 & $\alpha_{33}$ & 0.5050 & 0.1475 & 3.4242 & 0.0006 \\
$c_{31}$ & 0.0892 & 0.2021 & 0.4411 & 0.6591 & $\beta_{11}$ & 0.8952 & 0.0306 & 29.2619 & 0.0000 \\
$c_{32}$ & 0.5995 & 0.1477 & 4.0591 & 0.0000 & $\beta_{12}$ & 0.4363 & 0.0443 & 9.8516 \\
$c_{33}$ & 0.0000 & 0.0990 & 0.0000 & 1.0000 & $\beta_{13}$ & 0.4173 & 0.0491 & 8.5058 \\
$\alpha_{11}$ & -0.1747 & 0.0386 & -4.5234 & 0.0000 & $\beta_{21}$ & -0.1884 & 0.0548 & -3.4358 & 0.0000 \\
$\alpha_{12}$ & 0.1621 & 0.0640 & 2.5342 & 0.0113 & $\beta_{23}$ & 0.7609 & 0.0527 & 14.4489 & 0.0006 \\
$\alpha_{13}$ & 0.1442 & 0.0711 & 2.0276 & 0.0426 & $\beta_{23}$ & -0.1849 & 0.0606 & -3.0530 & 0.0023 \\
$\alpha_{21}$ & 0.0310 & 0.0730 & 0.4254 & 0.6705 & $\beta_{31}$ & 0.0879 & 0.0570 & 1.5414 & 0.1232 \\
$\alpha_{22}$ & -0.2024 & 0.1235 & -1.6390 & 0.1012 & $\beta_{32}$ & 0.0677 & 0.0764 & 0.8864 \\
$\alpha_{23}$ & -0.4307 & 0.1279 & -3.3683 & 0.0008 & $\beta_{33}$ & 0.9833 & 0.0864 & 11.3772 & 0.3754 \\
\hline
\end{tabular}

Table 9 shows that, at the 5\% significance level, the ARCH and the GARCH terms in variance equation $R_{t}^{S H F E}, R_{t}^{L M E}, R_{t}^{C O M E X}$ are significantly non-zero in the coefficient matrix elements $\alpha_{11}, \alpha_{33}, \beta_{11}, \beta_{22}, \beta_{33}$, indicating that there are both ARCH and GARCH effects in the logarithmic return sequence of copper futures in all three markets. Diagonal elements, $\alpha_{i i}$, reflect the sensitivity of the three markets to fluctuations. Moreover, $\alpha_{33}>\alpha_{11}>\alpha_{22}$ indicates that the yield of New York copper is the most sensitive to market changes, while that of London copper is the most sluggish. Diagonal elements, $\beta_{i i}$, reflect the memory of the three markets in terms of volatility, and $\beta_{33}>\beta_{11}>\beta_{22}$ indicates that the yield of New York copper has the strongest persistence to market volatility. 
Table 10 shows that, under the 5\% significance level, the original assumption that Shanghai, London, and New York copper have obvious bidirectional volatility spillover effects is rejected, that is, the condition equation of a copper futures market by the other two copper futures markets has shown early absolute residuals and is affected by the fluctuation of the early spread between the two market fluctuations; thus, for one market, the change will lead to the risk of spread to the other markets. Phase II (from 25 December 2008 to 29 January 2016) is shown in Table 11.

Table 10. Wald test of fluctuation spillover effect in the first stage.

\begin{tabular}{cccc}
\hline Null Hypothesis & Wald Test Statistic & $\boldsymbol{p}$ Value & Conclusion \\
\hline$\left(\alpha_{12}=\beta_{12}=0\right)$ & 50.5245 & 0.0000 & reject \\
$\left(\alpha_{21}=\beta_{21}=0\right)$ & 5.9025 & 0.0027 & reject \\
$\left(\alpha_{13}=\beta_{13}=0\right)$ & 37.4320 & 0.0000 & reject \\
$\left(\alpha_{31}=\beta_{31}=0\right)$ & 8.6802 & 0.0002 & reject \\
$\left(\alpha_{23}=\beta_{23}=0\right)$ & 19.2505 & 0.0000 & reject \\
$\left(\alpha_{32}=\beta_{32}=0\right)$ & 3.3307 & 0.0358 & reject \\
\hline
\end{tabular}

Table 11. BEKK variance equation estimation results in the second stage.

\begin{tabular}{cccccccccc}
\hline Factor & E-Value & S.E. & T Statistic & $\boldsymbol{p}$ Value & Factor & E-Value & S.E. & T Statistic & $\boldsymbol{p}$ Value \\
\hline$c_{11}$ & -0.0729 & 0.0259 & -2.8120 & 0.0049 & $\alpha_{31}$ & 0.0930 & 0.0283 & 3.2861 \\
$c_{21}$ & 0.1480 & 0.0980 & 1.5109 & 0.1308 & $\alpha_{32}$ & 0.0725 & 0.0479 & 1.5120 & 0.0010 \\
$c_{22}$ & 0.1526 & 0.1282 & 1.1902 & 0.2340 & $\alpha_{33}$ & -0.1732 & 0.0422 & -4.1007 & 0.0000 \\
$c_{31}$ & -0.0016 & 0.0902 & -0.0176 & 0.9860 & $\beta_{11}$ & 0.9104 & 0.0205 & 44.4746 & 0.0000 \\
$c_{32}$ & 0.1508 & 0.0832 & 1.8119 & 0.0700 & $\beta_{12}$ & -0.1258 & 0.0452 & -2.7851 & 0.0054 \\
$c_{33}$ & 0.0000 & 0.1039 & 0.0000 & 1.0000 & $\beta_{13}$ & -0.0507 & 0.0416 & -1.2184 & 0.2231 \\
$\alpha_{11}$ & 0.0249 & 0.0316 & 0.7880 & 0.4307 & $\beta_{21}$ & 0.0243 & 0.0292 & 0.8348 & 0.4038 \\
$\alpha_{12}$ & 0.1778 & 0.0588 & 3.0246 & 0.0025 & $\beta_{22}$ & 0.6825 & 0.0374 & 18.2256 & 0.0000 \\
$\alpha_{13}$ & 0.2988 & 0.0479 & 6.2415 & 0.0000 & $\beta_{23}$ & -0.2679 & 0.0374 & -7.1624 & 0.0000 \\
$\alpha_{21}$ & 0.0971 & 0.0310 & 3.1277 & 0.0018 & $\beta_{31}$ & 0.0443 & 0.0272 & 1.6301 & 0.1031 \\
$\alpha_{22}$ & -0.1701 & 0.0566 & -3.0079 & 0.0026 & $\beta_{32}$ & 0.4002 & 0.0325 & 12.3083 \\
$\alpha_{23}$ & 0.0636 & 0.0437 & 1.4529 & 0.1463 & $\beta_{33}$ & 1.2357 & 0.0303 & 40.7572 & 0.0000 \\
\hline
\end{tabular}

In Table 11, it is observed that, at the $1 \%$ significance level, elements $\alpha_{22}, \alpha_{33}, \beta_{11}, \beta_{22}$, $\beta_{33}$ of the ARCH and GARCH term coefficient matrix in variance equation $R_{t}^{S H F E}, R_{t}^{L M E}$, $R_{t}^{C O M E X}$ are significantly non-zero, indicating that both the ARCH and the GARCH effects exist, because $\alpha_{33}>\alpha_{11}>\alpha_{22}, \beta_{33}>\beta_{11}>\beta_{22}$ indicates that copper futures on the New York Exchange are the most sensitive and the most persistent to market movements.

Table 12 shows that, at the $1 \%$ significance level, all null hypotheses are rejected and there are obvious two-way fluctuation spillover effects between Shanghai, London, and New York copper pairs, which is consistent with the results for the first-stage test. Phase III (from 1 February 2016 to 30 June 2020) is shown in Table 13.

Table 12. Wald test of fluctuation spillover effect in the second stage.

\begin{tabular}{cccc}
\hline Null Hypothesis & Wald Test Statistic & $\boldsymbol{p}$ Value & Conclusion \\
\hline$\left(\alpha_{12}=\beta_{12}=0\right)$ & 21.3973 & 0.0000 & reject \\
$\left(\alpha_{21}=\beta_{21}=0\right)$ & 6.4725 & 0.0015 & reject \\
$\left(\alpha_{13}=\beta_{13}=0\right)$ & 37.0629 & 0.0000 & reject \\
$\left(\alpha_{31}=\beta_{31}=0\right)$ & 5.7898 & 0.0031 & reject \\
$\left(\alpha_{23}=\beta_{23}=0\right)$ & 37.0629 & 0.0000 & reject \\
$\left(\alpha_{32}=\beta_{32}=0\right)$ & 80.5532 & 0.0000 & reject \\
\hline
\end{tabular}


Table 13. BEKK variance equation estimation results in the third stage.

\begin{tabular}{cccccccccc}
\hline Factor & E-Value & S.E. & T Statistic & $p$ Value & Factor & E-Value & S.E. & T Statistic & $p$ Value \\
\hline$c_{11}$ & 0.2567 & 0.0625 & 4.1084 & 0.0000 & $\alpha_{31}$ & -0.0023 & 0.0705 & -0.0325 & 0.9741 \\
$c_{21}$ & 0.9050 & 0.2069 & 4.3736 & 0.0000 & $\alpha_{32}$ & -0.1773 & 0.1193 & -1.4855 & 0.1374 \\
$c_{22}$ & 0.7654 & 0.2028 & 3.7742 & 0.0002 & $\alpha_{33}$ & 0.5528 & 0.0904 & 6.1172 & 0.0000 \\
$c_{31}$ & 0.7208 & 0.2368 & 3.0438 & 0.0023 & $\beta_{11}$ & 0.9862 & 0.0438 & 22.5172 & 0.0000 \\
$c_{32}$ & 0.4521 & 0.2576 & 1.7550 & 0.0793 & $\beta_{12}$ & 0.2859 & 0.1213 & 2.3575 \\
$c_{33}$ & -0.0000 & 0.2555 & -0.0000 & 0.9999 & $\beta_{13}$ & 0.1817 & 0.0891 & 2.0402 & 0.0184 \\
$\alpha_{11}$ & -0.1488 & 0.0551 & -2.7010 & 0.0069 & $\beta_{21}$ & -0.2032 & 0.1276 & -1.5917 & 0.1115 \\
$\alpha_{12}$ & 0.1359 & 0.0833 & 1.6320 & 0.1027 & $\beta_{22}$ & 0.0113 & 0.2572 & 0.0441 & 0.0248 \\
$\alpha_{13}$ & -0.1191 & 0.0665 & -1.7906 & 0.0734 & $\beta_{23}$ & -0.3039 & 0.2031 & -1.4961 & 0.1346 \\
$\alpha_{21}$ & -0.0966 & 0.0503 & -1.9187 & 0.0550 & $\beta_{31}$ & 0.0210 & 0.0533 & 0.3946 & 0.6931 \\
$\alpha_{22}$ & 0.2042 & 0.0883 & 2.3135 & 0.0207 & $\beta_{32}$ & 0.1032 & 0.1397 & 0.7390 & 0.4599 \\
$\alpha_{23}$ & -0.3853 & 0.0676 & -5.6964 & 0.0000 & $\beta_{33}$ & 0.7635 & 0.0842 & 9.0659 & 0.0000 \\
\hline
\end{tabular}

In Table 13 , it is observed that, at the $5 \%$ significance level, diagonal factors $\alpha_{11}, \alpha_{22}$, $\alpha_{33}, \beta_{11}, \beta_{22}, \beta_{33}$ of the coefficient matrix of the ARCH and GARCH terms in invariance equation $R_{t}^{S H F E}, R_{t}^{L M E}, R_{t}^{C O M E X}$ are significantly non-zero, that is, both the $\mathrm{ARCH}$ and the GARCH effects exist. Because $\alpha_{33}>\alpha_{22}>\alpha_{11}$, the price of copper futures on the New York Exchange in the third stage is the most sensitive to market changes, while the price of copper futures on the Shanghai Futures Exchange is the slowest to react to the market changes. As $\beta_{11}$ is the largest and $\beta_{22}$ is the smallest, the copper futures on the Shanghai Exchange have the most persistent volatility in the third stage.

In Table 14, it is observed that, at the 5\% significance level, the null hypothesis of $\alpha_{32}=\beta_{32}=0$ and $\alpha_{31}=\beta_{31}=0$ cannot be rejected. It is believed that there is an obvious two-way fluctuation spillover effect between Shanghai and New York copper, that is, there is risk transmission between them. However, Shanghai and New York copper have only a one-way fluctuation spillover effect on London copper.

Table 14. Wald test of fluctuation spillover effect in the second stage.

\begin{tabular}{cccc}
\hline Null Hypothesis & Wald Test Statistic & $\boldsymbol{p}$-Value & Conclusion \\
\hline$\left(\alpha_{12}=\beta_{12}=0\right)$ & 3.8122 & 0.0221 & reject \\
$\left(\alpha_{21}=\beta_{21}=0\right)$ & 5.4261 & 0.0044 & reject \\
$\left(\alpha_{13}=\beta_{13}=0\right)$ & 5.2046 & 0.0055 & reject \\
$\left(\alpha_{31}=\beta_{31}=0\right)$ & 0.1174 & 0.8892 & reject \\
$\left(\alpha_{23}=\beta_{23}=0\right)$ & 23.5138 & 0.0000 & reject \\
$\left(\alpha_{32}=\beta_{32}=0\right)$ & 1.1512 & 0.3163 & reject \\
\hline
\end{tabular}

\subsection{Analysis of the Linkage Effect of Copper Futures Market from the Perspective of Leap}

This study uses Matlab software and the BN-S non-parametric test method to study jump times, jump proportion, and joint jump times of single copper futures markets, between two markets and between all three markets. Considering the difficulty of obtaining high-frequency data on copper futures prices, this paper approximates the daily closing logarithmic yield of each week's copper futures price as the intercell replacement of intraday high-frequency data and obtains complete data for 580 weeks through data cleaning.

\subsubsection{Analysis of the Number of Jumps in a Single Market}

Table 15 shows that, at the $1 \%$ significance level, the copper futures have jumped in all three markets. Among them, Shanghai copper has 11 jumps, accounting for $1.9 \%$. There were 16 jumps of LME copper, accounting for $2.76 \%$, and there were 15 jumps of New York copper, accounting for $2.59 \%$. At the same time, when the significance level increases to $5 \%$ and $10 \%$, the number of jumps in all three markets increases significantly. 
Table 15. Jump times for a single market.

\begin{tabular}{cccc}
\hline Significance Level & Market & Jumping Frequency & Jump Proportion \\
\hline \multirow{2}{*}{$1 \%$} & SHFE & 11 & 0.0191 \\
& LME & 16 & 0.0276 \\
& COMEX & 15 & 0.0259 \\
\hline \multirow{2}{*}{$5 \%$} & SHFE & 52 & 0.0897 \\
& LME & 61 & 0.1052 \\
& COMEX & 72 & 0.1241 \\
\hline \multirow{2}{*}{$10 \%$} & SHFE & 101 & 0.1741 \\
& LME & 98 & 0.1690 \\
& COMEX & 103 & 0.1776 \\
\hline
\end{tabular}

By comparing the jump data of the three markets, the jump proportion of each market is similar, indicating that the difference of extreme volatility of the three markets is not obvious. Overall, New York Copper has the highest degree of extreme volatility and the greatest risk, while Shanghai copper has the lowest degree of extreme volatility and is relatively stable.

\subsubsection{Analysis of the Number of Joint Market Jumps}

The test results for the joint jumps between two markets and three markets are shown in Tables 16 and 17, respectively.

Table 16. A number of linkage jumps between two markets.

\begin{tabular}{ccc}
\hline Significance Level & Market & Joint Jumping Frequency \\
\hline \multirow{2}{*}{$1 \%$} & SHFE, LME & 0 \\
& SHFE, COMEX & 0 \\
& LME, COMEX & 4 \\
\hline \multirow{2}{*}{$5 \%$} & SHFE, LME & 7 \\
& SHFE, COMEX & 4 \\
& LME, COMEX & 30 \\
\hline \multirow{2}{*}{$10 \%$} & SHFE, LME & 19 \\
& SHFE, COMEX & 22 \\
\end{tabular}

Table 16 shows that, at the $1 \%$ significance level, only four joint jumps occurred between LME and COMEX copper. With the increase in significance level, the number of joint jumps between the two markets increased significantly. The number of joint jumps between Shanghai and London copper and Shanghai and New York copper is significantly lower than that between London and New York copper, indicating the latter joint jumps are relatively stronger.

Table 17. Joint jumps between the three markets.

\begin{tabular}{ccc}
\hline Significance Level & Market & Joint Jumping Frequency \\
\hline $1 \%$ & SHFE, LME, COMEX & 0 \\
$5 \%$ & SHFE, LME, COMEX & 2 \\
$10 \%$ & SHFE, LME, COMEX & 7 \\
\hline
\end{tabular}

Table 17 shows that, at each significance level, the number of joint jumps among the three markets is small, but an increase in the significance level increases the number of joint jumps among the three markets, indicating that the three markets have a certain degree of a linkage under special circumstances, but the correlation degree is weak. 
In summary, over the entire sample period, copper futures contracts in a single market all show a jump phenomenon. When the significance level is low, the joint jump phenomenon between markets is not obvious and the number of jumps is small. With the increase in the significance level, the number of jumps in a single market and of joint jumps between markets increases significantly.

\subsubsection{Correlation Analysis of Jump Spillover Intensity}

Based on formula (13), the simultaneous jump intensity between Shanghai copper and itself is 0.0165 , that between New York copper and itself is 0.0228 , that between London copper and itself is 0.0193 , and that of the three markets is 0.0006 .

Therefore, the jump intensity of the New York copper market is higher than that of the London and Shanghai copper markets, while the three markets have smaller jump intensities.

\subsubsection{Conditional Jump Spillover Probability Analysis}

Based on Formula (14), the conditional overflow probability of Shanghai copper based on New York copper is 0.0278 and that of Shanghai copper based on London copper is 0.0328 .

Therefore, at the $5 \%$ significance level, there is a jump spillover effect between the domestic and foreign copper futures markets, and the jump behavior of the London copper futures market has a more significant impact on the Shanghai copper futures market than the New York copper futures market.

\section{Conclusions}

In SHFE and for 3 months continuous trading on the COMEX, and considering the financial crises in 2008 and 2015 and China's stock market crash, this study explores jump diffusion considering the relationships between the three copper futures markets using the ADF unit root test, the E-G co-integration test, the Granger causality test, impulse response and variance decomposition analysis, the BEKK model, and the BN-S non-parametric test. Based on the empirical analysis results, the following conclusions can be drawn:

(1) The copper futures contracts in Shanghai, London, and New York exchanges have long-term co-integration and short-term equilibrium relations. The fact that there exists a long-term equilibrium relationship between the three copper futures markets means there is no arbitrage equilibrium between the domestic and international copper futures markets, and the pricing of Shanghai copper futures is reasonable in overseas markets. The price of Shanghai copper futures has an automatic repair mechanism from the short-term change to long-term equilibrium improvement, and the improvement rate is continuously increasing.

(2) There is a significant bidirectional mean spillover effect between London and New York copper, while Shanghai Copper had a unidirectional mean spillover effect on London and New York copper. Before the stock market crash, there was a significant two-way fluctuation spillover effect between Shanghai, New York, and London copper. After the stock market crash, Shanghai and New York copper show a significant oneway fluctuation spillover effect on London copper. The volatility spillover coefficient of the London futures market and the New York futures market is larger than that of the Shanghai futures market, which indicates that, in the transmission process of volatility risk, the other two futures markets have the advantage, and the Shanghai futures market is in a passive position.

(3) Compared with the impact effect of the Shanghai futures market, when it impacts the New York futures market, the performance of the Shanghai futures market and the New York futures market is obvious; both have a larger reaction in the first phase, and the chance of cross-market arbitrage between markets is smaller. When it hits the London market, the performance of the Shanghai market and the London market 
is quite different, and there is a big chance of cross-market arbitrage between the markets.

(4) During the sample period, there were jumps only in a single market. At a low significance level, the joint jumps between markets were not obvious, but with an increase in the significance level, the number of joint jumps between markets increased significantly.

Through the BN-S nonparametric test, it can be seen that Shanghai, New York, and London copper all have the phenomenon of the jump. When the significance level increases, the jump times and jump proportion of the three markets all increase significantly. At the same time, the New York copper market has the highest extreme volatility and the highest risk, while SHFE has the lowest extreme volatility and is more stable. When the significance level is low, no joint jumps occur between Shanghai and London copper and Shanghai and New York copper, and the number of joint jumps between London and New York copper is also less. With the increase of significance level, the number of joint jumps between the two markets increases significantly. At the same time, the London and New York copper markets are more closely linked. The number of joint jumps among the three markets is small, and the number of joint jumps increases with the increase of significance level, which indicates that the three markets have a certain degree of correlation effect in extreme cases, but the degree of correlation is weak.

Author Contributions: Conceptualization, X.J. and K.Y.; formal analysis, X.J.; methodology, X.J. and S.Z.; data curation, S.Z. and M.L.; writing-original draft, X.J., S.Z. and M.L.; writing-review and editing, X.J.; supervision, K.Y. All authors have read and agreed to the published version of the manuscript.

Funding: This research was funded by the National Social Science Foundation of China (Grant No. 18CJY018).

Institutional Review Board Statement: Not applicable.

Informed Consent Statement: Not applicable.

Data Availability Statement: The data presented in this study are available on request from the corresponding author.

Acknowledgments: The authors are grateful to the International Postdoctoral Exchange Fellowship Program. We offer our sincere thanks to the editor and anonymous reviewers for their careful evaluation and their fruitful observations, suggestions, corrections, and recommendations that substantially improved the initial manuscript.

Conflicts of Interest: The authors declare no conflict of interest.

\section{References}

1. Banerjee, A. Simple Model of Herd Behavior. Q. J. Econ. 1992, 107, 797-817. [CrossRef]

2. Bae, H.O.; Cho, S.Y.; Kim, J.; Yun, S.B. A Kinetic Description for the Herding Behavior in Financial Market. J. Stat. Phys. 2019, 176, 398-424. [CrossRef]

3. Lu, J.; Zheng, L. Research on contagion effect of the international capital market during the subprime crisis. Int. Financ. Res. 2012, 5, 83-91.

4. Cao, G.; Cao, J.; Xu, L.; He, L. Detrended cross-correlation analysis approach for assessing asymmetric multifractal detrended cross-correlations and their application to the Chinese financial market. Phys. Stat. Mech. Appl. 2014, 393, 460-469. [CrossRef]

5. Engle, R.F.; Granger, C.W.J. Cointegration and error correction, representation, estimation and testing. Econometrica 1987, 55, 251-276. [CrossRef]

6. Gong, C.C.; Ji, S.D.; Su, L.L.; Li, S.P.; Ren, F. The lead-lag relationship between stock index and stock index futures: A thermal optimal path method. Phys. Stat. Mech. Appl. 2016, 444, 63-72. [CrossRef]

7. Zhang, Y.H.; Liu, L. The lead-lag relationships between spot and futures prices of natural gas. Phys. Stat. Mech. Appl. 2018, 490, 203-211. [CrossRef]

8. Lv, Z.; Chu, A.M.; McAleer, M.; Wong, W.K. Modelling Economic Growth, Carbon Emissions, and Fossil Fuel Consumption in China: Cointegration and Multivariate Causality. Res. Public Health 2019, 16, 4176. [CrossRef]

9. Zhou, B.; Wu, C. Intraday dynamic relationships between CSI 300 index futures and spot markets: A high-frequency analysis. Neural Comput. Appl. 2016, 27, 1007-1017. [CrossRef] 
10. Chang, C.Y.; Lai, J.Y.; Chuang, I.Y. Futures hedging effectiveness under the segmentation of bear/bull energy markets. Energy Econ. 2010, 32, 442-449. [CrossRef]

11. Guo, S.-H.; Wang, H.; Gao, Z.-B.; Wand, L.-X. Research on price linkage and fluctuation of metal futures market-taking SHFE and LME copper and lead as examples. Int. Financ. Inst. 2010, 4, 79-88.

12. Wang, Y.; Sun, B. Analysis of the interaction between Shanghai and London copper futures prices based on SVAR model. Bus. Chron. 2014, 22, 88-89.

13. Gulley, A.; Tilton, J.E. The relationship between spot and futures prices: An empirical analysis. Resour. Policy 2014, 41, 109-112. [CrossRef]

14. Yue, Y.D.; Liu, D.C.; Shan, X.U. Price linkage between Chinese and international nonferrous metals commodity markets based on VAR-DCC-GARCH models. Trans. Nonferrous Met. Soc. China 2015, 25, 1020-1026. [CrossRef]

15. Mayer, H.; Rathgeber, A.; Wanner, M. Financialization of metal markets: Does futures trading influence spot prices and volatility? Resour. Policy 2017, 53, 300-316. [CrossRef]

16. Song, B.; Xing, T. Comparative study on the influence of Shanghai copper, London copper and new copper market in China. Price Econ. Pract. 2018, 3, 121-124.

17. Xia, R.; Wu, J. Discussion on the linkage of domestic nonferrous metal commodity prices based on VAR-DCC-GARCH model. Finance 2020, 3, 101.

18. Hui, X.; Yao, X.; Ma, Y. Research on the influence of night trading on China's precious metal futures market. Oper. Res. Manag. 2020, 29, 207-217.

19. Hull JWhite, A. The Pricing of Options on Assets with Stochastic Volatilities. J. Financ. 1987, 42, 281-300. [CrossRef]

20. Duffie, D.; Pan, J.; Singleton, K. Transform Analysis and Asset Pricing for Affine Jump-Diffusions. Econometrica 2000, 68, 1343-1376. [CrossRef]

21. Zhong, M.; Darrat, A.F.; Otero, R. Price discovery and volatility spillovers in index futures markets: Some evidence from Mexico. J. Bank Financ. 2004, 28, 3037-3054. [CrossRef]

22. Jacod, J.; Todorov, V. Testing for common arrivals of jumps for discretely observed multidimensional processes. Ann. Stat. 2009, 37, 1792-1838. [CrossRef]

23. Gilde, D. An empirical investigation of intraday jumps and cojumps in us equities. Work. Pap. 2009. [CrossRef]

24. Wang, C.; Hao, P.; Fang, Z. Research on the jumping model of securities market in continuous time financial framework. Nankai Econ. Res. 2009, 5, 143-152.

25. Chen, L.; Sun, J. Research on the jumping behavior of asset returns in the stock market. Econ. Res. 2010, 4, 54-66.

26. Chen, G.; Wang, Z. Empirical study on the continuous fluctuation and jumping fluctuation of China's stock market. Syst. Eng. Theory Pract. 2010, 30, 1554-1562.

27. Liu, Z.; Xu, J. Comparative study on non-parametric test method of financial asset price jump based on Monte Carlo simulation. Res. Quan. Econ. Technol. 2016, 33, 128-145.

28. Cao, W.; Guernsey, B. Evidence of infinite and finite jump processes in commodity futures prices: Crude oil and natural gas. Phys. Stat. Mech. Appl. 2018, 502, 629-641. [CrossRef]

29. Gong, X.; Xiong, X.; Zhuang, X. Research on the volatility of stock index futures under the jumping diffusion model with generalized two-index distribution. Manag. Sci. 2015, 31, 149-159.

30. Guo, Y.; Yao, S.; Cheng, H.; Zhu, W. China's copper futures market efficiency analysis: Based on nonlinear Granger causality and multifractal methods. Resour. Policy 2020, 68, 101716. [CrossRef]

31. Yu, H.; Ding, Y.; Sun, Q.; Gao, X.; Jia, X.; Wang, X.; Guo, S. Multi-scale comovement of the dynamic correlations between copper futures and spot prices. Resour. Policy 2020, 70, 101193. [CrossRef]

32. Yang, B. Review of financial asset price jump: From discovery to focusing test. Technol. Ind. 2020, $20,74-80$.

33. Carpinteyro, M.; Venegas-Martínez, F.; Aali-Bujari, A. Venegas-Martínez and A. Aali-Bujari, Modeling Precious Metal Returns through Fractional Jump-Diffusion Processes Combined with Markov Regime-Switching Stochastic Volatility. Mathematics 2021, 9, 407. [CrossRef]

34. Engle, R.F.; Kroner, K.F. Multivariate Simultaneous Genera lized ARCH. Econom. Theory 2000, 11, 122-150. [CrossRef]

35. Naeem, M.A.; Farid, S.; Nor, S.M.; Shahzad, S.J.H. Spillover and Drivers of Uncertainty among Oil and Commodity Markets. Mathematics 2021, 9, 441. [CrossRef]

36. Wang, X. Pricing options on the maximum or minimum of multi-assets under jump-diffusion processes. Int. Rev. Econ. Financ. 2020, 70, 16-26. [CrossRef]

37. Yin, K.D.; Liu, Z.; Jin, X. Interindustry volatility spillover effects in China's stock market. Phys. Stat. Mech. Appl. 2020, 539, 122936. [CrossRef] 